\title{
Lithium chloride attenuates cell death in oculopharyngeal muscular dystrophy by perturbing Wnt/ $\beta$-catenin pathway
}

\author{
A Abu-Baker ${ }^{1}$, J Laganiere ${ }^{1}$, R Gaudet ${ }^{2}$, D Rochefort ${ }^{1}$, B Brais ${ }^{2}$, C Neri ${ }^{3}$, PA Dion ${ }^{1,4}$ and GA Rouleau ${ }^{*, 1}$
}

Expansion of polyalanine tracts causes at least nine inherited human diseases. Among these, a polyalanine tract expansion in the poly (A)-binding protein nuclear 1 (exp PABPN1) causes oculopharyngeal muscular dystrophy (OPMD). So far, there is no treatment for OPMD patients. Developing drugs that efficiently sustain muscle protection by activating key cell survival mechanisms is a major challenge in OPMD research. Proteins that belong to the Wnt family are known for their role in both human development and adult tissue homeostasis. A hallmark of the Wnt signaling pathway is the increased expression of its central effector, beta-catenin ( $\beta$-catenin) by inhibiting one of its upstream effector, glycogen synthase kinase (GSK)3 $\beta$. Here, we explored a pharmacological manipulation of a Wnt signaling pathway using lithium chloride (LiCl), a GSK-3 $\beta$ inhibitor, and observed the enhanced expression of $\beta$-catenin protein as well as the decreased cell death normally observed in an OPMD cell model of murine myoblast (C2C12) expressing the expanded and pathogenic form of the exp PABPN1. Furthermore, this effect was also observed in primary cultures of mouse myoblasts expressing exp PABPN1. A similar effect on $\beta$-catenin was also observed when lymphoblastoid cells lines (LCLs) derived from OPMD patients were treated with LiCl. We believe manipulation of the Wnt/ $\beta$-catenin signaling pathway may represent an effective route for the development of future therapy for patients with OPMD.

Cell Death and Disease (2013) 4, e821; doi:10.1038/cddis.2013.342; published online 3 October 2013

Subject Category: Neuroscience

Oculopharyngeal muscular dystrophy (OPMD) is a midlife onset hereditary disease affecting skeletal muscles with minor neuronal involvement. ${ }^{1-3}$ The disease is characterized by swallowing difficulties, eyelid drooping and intranuclear inclusions (INI) in muscle. ${ }^{4}$ OPMD is caused by expansions of the short (GCG) trinucleotide repeat in the coding sequence of the poly $(\mathrm{A})$-binding protein nuclear $1(P A B P N 1)$ gene. ${ }^{5}$ The normal $P A B P N 1$ gene has a $(\mathrm{GCG})_{6}$ repeat encoding a polyalanine (polyA) stretch at the $5^{\prime}$-end, while in OPMD patients this repeat is expanded to $(\mathrm{GCG})_{8-13}(\exp P A B P N 1){ }^{5}$ Although there is no specific treatment for OPMD, efforts have been directed on enhancing the protein-folding capacity, ${ }^{6-9}$ reducing aggregate formation and apoptosis, ${ }^{9-11}$ and modulating the activity of longevity modulators such as the sirtuins. ${ }^{12}$

The Wnt signal transduction cascade controls myriad biological phenomena throughout development and adult life of all animals. Aberrant Wnt signaling underlies a wide range of pathologies in the human. ${ }^{13}$ The Wnt proteins belong to a large family of secreted signaling molecules that act through distinct canonical and non-canonical pathways. The Wnt pathway participates in multiple developmental events during embryogenesis and has also been implicated in adult tissue homeostasis. ${ }^{14-16}$ Among the cellular processes in which they are involved are proliferation, survival, differentiation, and motility. ${ }^{15-17}$ Currently, three different pathways are believed to be activated upon Wnt receptor activation: (1) the best understood canonical $\beta$-catenin cascade, ${ }^{15,17}$ (2) the noncanonical planar cell polarity (PCP) pathway, ${ }^{18}$ and (3) the Wnt/Ca2 + pathway. ${ }^{19}$ A critical and the most studied Wnt pathway is canonical Wnt signaling, which functions by regulating the amount of transcriptional co-activator $\beta$-catenin that controls key developmental gene expression programs. ${ }^{20}$ $\beta$-catenin has a central role in cell adhesion, embryogenesis, cell fate regulation, and homeostatic processes. ${ }^{21-24}$ The Binding of Wnt to the frizzled (Fzd) receptor activates disheveled (Dvl) that leads to the inactivation of glycogen synthase kinase-3 (GSK-3). ${ }^{25}$ Upon the inhibition of GSK-3 $\beta$, $\beta$-catenin becomes stabilized, translocates to the nucleus, and interacts with a member of the DNA-binding protein

\footnotetext{
${ }^{1}$ The Montreal Neurological Institute and Hospital, Department of Medicine, McGill University, Montréal, Québec H3A2B4, Canada; ${ }^{2}$ Neuromuscular Group, The Montreal Neurological Institute and Hospital, McGill University, Montréal, Québec H3A2B4, Canada; ${ }^{3}$ Inserm, Unit 894, Laboratory of Neuronal Cell Biology and Pathology, Psychiatry and Neuroscience Center, 75014 Paris, France and ${ }^{4}$ Department of Medicine, Université de Montréal, Montréal, Québec H2L2W5, Canada *Corresponding author: GA Rouleau, The Montreal Neurological Institute and Hospital, McGill University, 3801 rue University, Montreal, Québec H3A2B4, Canada. Tel: +514-398-1903; Fax: +514-412-7602; E-mail: guy.rouleau@mcgill.ca

Keywords: Wnt pathway; poly (A) binding protein nuclear 1 (PABPN1); beta-catenin ( $\beta$-catenin); oculopharyngeal muscular dystrophy (OPMD); lithium chloride (LiCl) Abbreviations: OPMD, (oculopharyngeal muscular dystrophy); INI, intranuclear inclusions; PABPN1, poly (A) binding protein nuclear 1; exp PABPN1, expanded PABPN1; Fzd, frizzled; PCP, planar cell polarity; TCF, T-cell factor; GSK-3, glycogen synthase kinase-3; BIO, 6-bromoindirubin-3'-oxime; LCLs, lymphoblastoid cell lines; LiCl, lithium chloride; FACS, fluorescence-activated cell sorting; FFC, fluorescence flow cytometry; wtPABPN1-10Ala, wild-type PABPN1-10 Alanines; exp PABPN113 Ala, expanded PABPN1-13 Alanines; 7AAD, 7-aminoactinomycin D; GM, growth medium; DM, differentiation medium; $\beta$-catenin, beta-catenin; S.E., standard error Received 12.3.13; revised 05.7.13; accepted 02.8.13; Edited by H-U Simon
} 
family, the lymphoid enhancer factor and TCF (T-cell factor). Together the two proteins activate the transcription of specific genes such as cyclin D1, CBP, and Pitx2, ${ }^{26-28}$ leading to the increased activity of Wnt responsive gene transcription. ${ }^{29}$

Abnormal Wnt/ $\beta$-catenin signaling has been shown to be associated with many human diseases, including cancer, osteoporosis, aging, and degenerative disorders. ${ }^{16,17}$ GSK- $3 \beta$ is a key enzyme in Wnt signaling. GSK-3 $\beta$ has a central role in many cellular functions, contributing to the regulation of apoptosis, cell cycle, cell polarity, and gene expression. ${ }^{30-32}$ Recently, GSK-3 $\beta$ inhibitors have arisen as promising drugs for several pathologies such as diabetes, stroke, mood disorders, inflammation, and Alzheimer's disease. ${ }^{33}$ We previously used an OPMD $C$. elegans model to report observations that support the contribution of Wnt signaling pathway to the cell death associated with exp PABPN1. ${ }^{34}$ Furthermore, exposing animals from this model to the GSK-3 $\beta$ inhibitor 6-bromoindirubin-3'-oxime (BIO) showed that it protected muscle cells from the normally observed exp PABPN1 toxicity. To investigate this pathway in a mammalian cell environment more similar to the one of patients, we began using the mammalian cell line, mouse myoblasts (C2C12), primary culture of mouse myoblasts, and OPMD patients lymphoblastoid cell lines (LCLs), to examine if modulation of the Wnt signaling would also prove beneficial in these cells. As GSK-3- $\beta$ may be able to regulate polyalanineassociated pathogenesis, lithium was an obvious choice to test as a possible pharmacological modulator for OPMD, as it inhibits GSK-3- $\beta$. For this purpose, we elected to use lithium chloride ( $\mathrm{LiCl}$ ); a molecule that could rapidly be administered to OPMD patients if it could be shown to be as protective as $\mathrm{BIO}$ had been in the $C$. elegans model. $\mathrm{LiCl}$ is an FDA approved drug already used for the treatment of epilepsy and bipolar disorder patients. ${ }^{35,36}$ In the present report, we observed that $\mathrm{LiCl}$ can rescue cell death normally associated with the expression of exp PABPN1 in mammalian cells. This protection appears to be associated with the increase of $\beta$-catenin following the inhibition of GSK-3- $\beta$ by the compound. Both in vivo live-stage imaging microscopy and fluorescenceactivated cell sorting (FACS) methods were used to measure the protective effect of $\mathrm{LiCl}$ in an OPMD cell model of murine myoblast (C2C12) cells expressing exp PABPN1 as well as in primary culture of mouse myoblasts also expressing exp PABPN1. The manipulation of the Wnt pathway using $\mathrm{LiCl}$ in OPMD patients may therefore represent a genuine therapeutic avenue.

For the first time, our results provide exciting support for the use of $\mathrm{LiCl}$ as a possible treatment for OPMD. Our data, therefore, suggest that a promising strategy to elicit Wnt/ $\beta$ catenin-dependent muscle protection in the OPMD may be the administration of low doses of $\mathrm{LiCl}$, as this molecule is able to inhibit GSK-3 $\beta$ activity. ${ }^{37}$

\section{Results}

Dose-response experiments of LiCl. Glycogen synthase kinase-3 (GSK-3 $\beta$ ) is a highly conserved protein constitutively active serine/threonine kinase ubiquitously expressed in eukaryotes. $^{38}$ It has been implicated in many fundamental cellular functions, such as the cell cycle, gene transcription, and apoptosis, as a result of its ability to phosphorylate key proteins that modulate these processes. ${ }^{32}$ We investigated whether GSK-3- $\beta$ inhibitor, LiCl, could be a promising drug for OPMD treatment. At first, we established the appropriate dose of $\mathrm{LiCl}$ to be used on $\mathrm{C} 2 \mathrm{C} 12$ cells and monitored the number of viable cells exposed to different doses of $\mathrm{LiCl}$ in comparison with untreated control cells. This cell survival tracking assay was done over 6 days using a live-stage microscope and we found that $2.5 \mathrm{mM} \mathrm{LiCl}$ yielded the best cell survival rate. At dose $2.5 \mathrm{mM}, \mathrm{LiCl}$ maintains growth proliferation and survival of $\mathrm{C} 2 \mathrm{C} 12$ cells (Figure 1). This concentration of $\mathrm{LiCl}$ mimics the extracellular fluid levels that would be observed in vivo with doses used to treat bipolar disorder patients. ${ }^{39}$ At 10 and $15 \mathrm{mM}, \mathrm{LiCl}$ was toxic and caused the cells to die and detach from the culture dish. Thus, we chose $2.5 \mathrm{mM}$ of $\mathrm{LiCl}$ to continue with our study. Figure 1 represents the effects of different doses of $\mathrm{LiCl}$ on the morphology and survival of $\mathrm{C} 2 \mathrm{C} 12$ cells.

LiCl decreases exp PABPN1-associated cell death. We previously used transfection assays to establish that the transient expression of a GFP-tagged full-length cDNA of expanded PABPN1 (GFP-expPABPN1-13Ala and 17Ala) in various cell lines leads to significantly more cell death than what can be seen in transfections made with a corresponding vector expressing wild-type PABPN1 (GFP- ${ }_{w t} P A B P N 1-$ 10Ala). ${ }^{6,40}$ In order to test the effect of $\mathrm{LiCl}$ on cell death associated with exp PABPN1 expression, C2C12 cells were pretreated with $2.5 \mathrm{mM} \mathrm{LiCl}$ for 3 days before transfection and this treatment was maintained after transfection was made. Cells were transiently transfected with GFP-exp PABPN1-13Ala, GFP-exp PABPN1-17Ala, and the controls GFP- ${ }_{w t} P A B P N 1-10 A l a$, as well as with GFP alone. Control samples, where no drug was applied on corresponding transfected cells, were also monitored. We first followed cell viability using automated live-stage fluorescent microscopy to monitor the number of viable green fluorescent cells over 6 days post transfection. We looked at nuclear morphology, and GFP-expressing cells with fragmented or condensed nuclei were counted as dead. The automated microscope precisely returned back to same cell population field. $\mathrm{LiCl}$ treatment showed a consistent and significant protective effect against exp PABPN1-induced cell death, compared with non-treated counterparts. As shown in Figure $2 \mathrm{a}, \mathrm{LiCl}$ rescues cells expressing GFP-expPABPN1-13Ala and GFP-exp $P A B P N 1-17 A$ la-associated cell death $\left({ }^{\star} P<0.001\right.$ versus non-treated samples). LiCl treatment did not show a reduction of protein aggregation (data not shown). In order to validate this live imaging cell survival assay, we used a fluorescence-based flow cytometry (FFC) assay to analyze the ability of cells to exclude the red-fluorescent 7-aminoactinomycin D (7AAD) biomarker for dead cells. The presence of the GFP-tag in the expression vectors used enabled us to establish the fraction of $\mathrm{C} 2 \mathrm{C} 12$ cells that were actually transfected. The use of GFP has been described as a means to assess gene expression and transfection efficiency. ${ }^{41,42}$

The subset of these green cells that were dying and had compromised membranes were co-stained in red by the $7 A A D$, in opposition to transfected cells with intact cell membranes that remain green. Using this second method, 


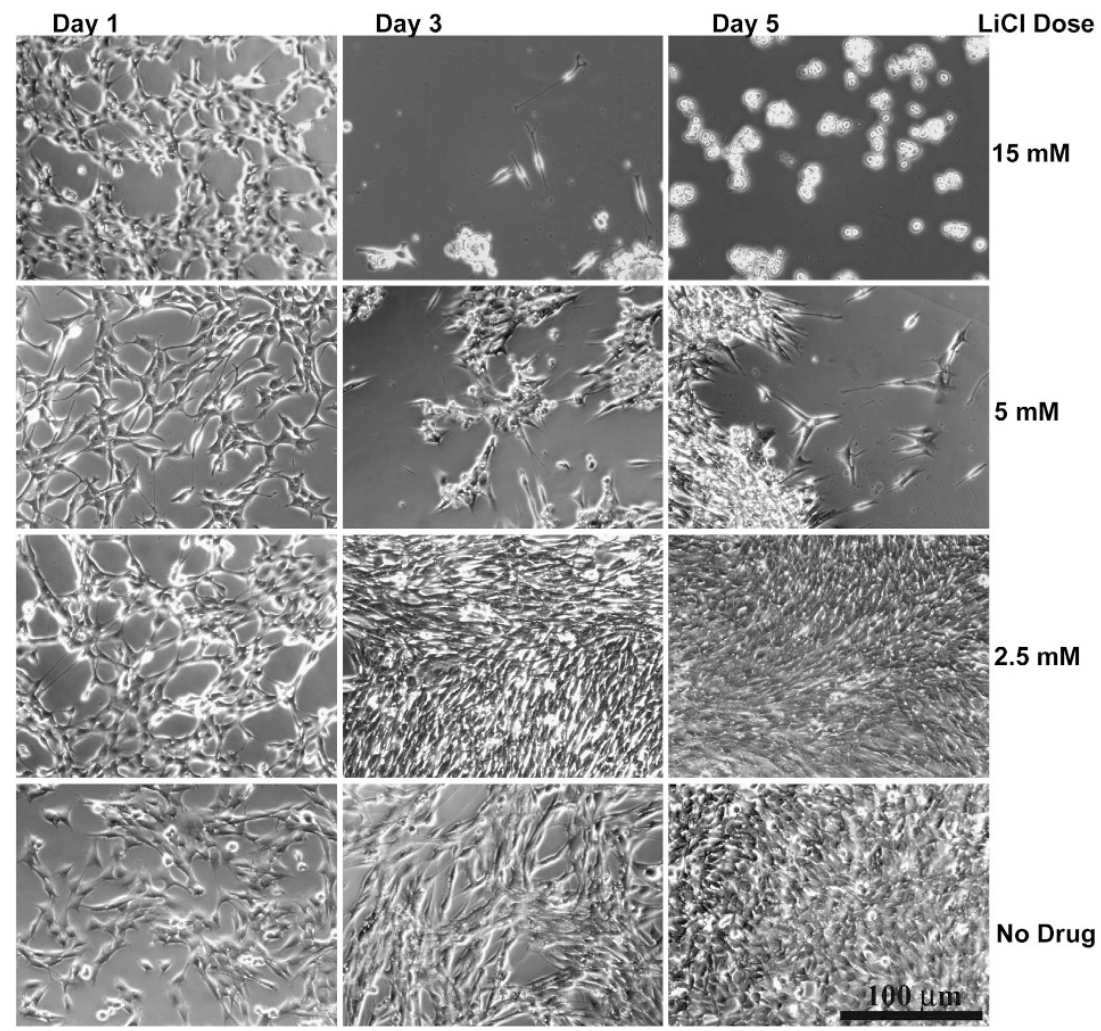

Figure 1 Choosing the best concentration of $\mathrm{LiCl}$ on the $\mathrm{C} 2 \mathrm{C} 12$ cell line. $\mathrm{LiCl}$ (GSK inhibitor) at $2.5 \mathrm{mM}$ maintains growth, size, and proliferation of $\mathrm{C} 2 \mathrm{C} 12 \mathrm{muscle}$ cells. A dose-response experiment on non-transfected $\mathrm{C} 2 \mathrm{C} 12$ cells shows that with a low dose of $2.5 \mathrm{mM} \mathrm{LiCl}$, the cells maintain their growth and survival similarly to untreated cells. Cells were monitored under a live-stage Leica DMI 6000 microscope for morphology and viability. Phase images were captured at the indicated days after LiCl treatment. Higher concentrations of $\mathrm{LiCl}$ at 5 and $15 \mathrm{mM}$ (top two rows) were toxic and caused the cells to die, while a concentration of $2.5 \mathrm{mM} \mathrm{LiCl}$ maintained the cells healthy and in good shape for 6 days. Therefore, $2.5 \mathrm{mM} \mathrm{LiCl}$ was the chosen concentration throughout the study

the expression of GFP-exp PABPN1-13Ala, for example, was confirmed to lead to death in $\sim 82 \%$ of cells 6 days post transfection (Figure $2 b$ ). By comparison, the measured cell death associated with GFP-wtPABPN1-10Ala expression was $\sim 45 \%$ (Figure $2 b$ ). Using FFC, we then examined cell survival when $\mathrm{LiCl}$ was added to the media. We found, in the presence of $2.5 \mathrm{mM}$, that $\mathrm{C} 2 \mathrm{C} 12$ cells expressing GFP-exp PABPN1-13Ala or GFP-exp PABPN1-17Ala survived significantly longer than their untreated counterparts (Figure 2b). Figure 2c shows an example of FFC cell survival measured by 7AAD staining in cells expressing GFP-exp PABPN1-17Ala. The FFC dot blot in Figure 2c shows a significant lower number of dead cells (upper right quadrants, bottom FFC image) in $\mathrm{C} 2 \mathrm{C} 12$ cells expressing GFP-exp PABPN1-17Ala treated with $2.5 \mathrm{mM} \mathrm{LiCl}$ compared with untreated counterparts. Therefore, using the two approaches, we conclude that $\mathrm{LiCl}$ is protective to cells transfected with GFP-exp PABPN1 (13Ala and 17Ala), suggesting that inhibition of GSK-3 $\beta$ can be beneficial in OPMD.

\section{$\mathrm{LiCl}$ treatment enhances the proliferation and differentiation} of $\mathrm{C} 2 \mathrm{C} 12$ cells expressing GFP-exp PABPN1 (13Ala and 17Ala). In order to investigate how myogenic cells morphologically respond to $\mathrm{LiCl}$ treatment, transected C2C12 cells treated with $2.5 \mathrm{mM} \mathrm{LiCl}$ were cultivated in growth medium (GM) for $24 \mathrm{~h}$, which was then replaced by differentiation medium (DM) for a further period of 6 days. To evaluate the effect of $\mathrm{LiCl}$ on $\mathrm{C} 2 \mathrm{C} 12$ differentiation, we followed the morphology of non-transfected $\mathrm{C} 2 \mathrm{C} 12$ cells in parallel to the $\mathrm{C} 2 \mathrm{C} 12$ cells expressing either GFP- ${ }_{\text {wt }}$ PABPN1-10Ala, or GFP-exp PABPN1-13Ala or GFP-exp PABPN1-17Ala or GFP in the presence of $2.5 \mathrm{mM}$ $\mathrm{LiCl}$. In control samples, with cells expressing GFP- ${ }_{\text {wt }}$ PABPN1-10Ala or GFP, LiCl maintains the ability of cells to proliferate and differentiate over the time course (Figures $3 \mathrm{a}$ and $\mathrm{b}$ ). Our results show that $\mathrm{LiCl}$ enhances the ability of $\mathrm{C} 2 \mathrm{C} 12$ expressing GFP-exp PABPN1-17Ala to differentiate from single-cell myoblasts to multinucleated myotubes (Figure 3c). In addition to enhancing the multinucleated differentiation myotubes, the drug enhances the

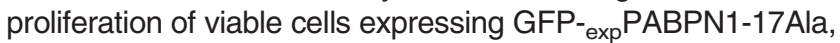
as detected under the live-stage fluorescent microscope (Figure $3 c$ ). Similar findings were also obtained from cells expressing GFP-exp PABPN1-13Ala (Figure 3d). $\mathrm{LiCl}$ treatment was found to increase myotube formation as a majority of nuclei were present in large multinucleated myotubes after 6 days in DM (Figure 3d). Phase microscopy was used to visualize myotube formation and the morphology of cells. In order to quantitatively evaluate the effect of $\mathrm{LiCl}$ on the differentiation grade of $\mathrm{C} 2 \mathrm{C} 12$ cells expressing

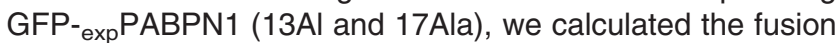
index of the cultures. The results presented in Figure 4 

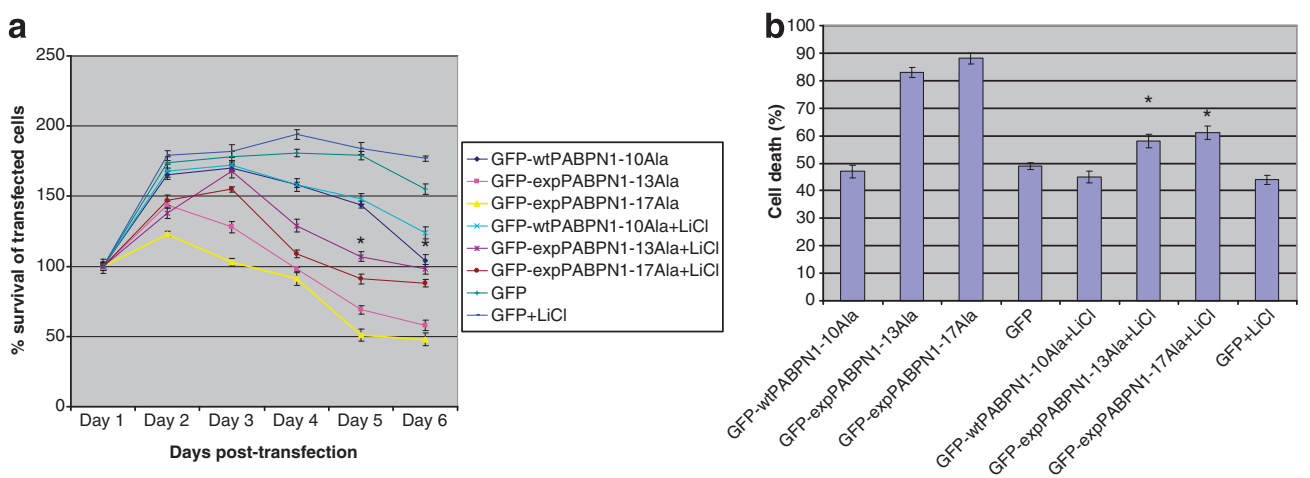

C expPABPN1-17Ala / No drug

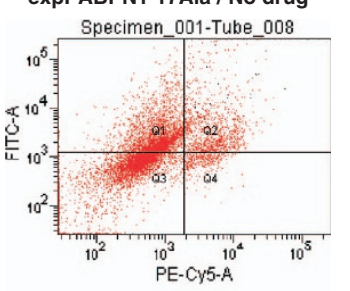

\begin{tabular}{|lll|}
\hline Population & \#Events & \%Parent \\
Q1 & 3,406 & 34.1 \\
Q2 & $\underline{\mathbf{1 , 3 2 5}}$ & 13.2 \\
Q3 & 4,809 & 48.1 \\
Q4 & 460 & 4.6 \\
\hline
\end{tabular}

expPABPN1-17Ala $+2.5 \mathrm{mM} \mathrm{LiCl}$

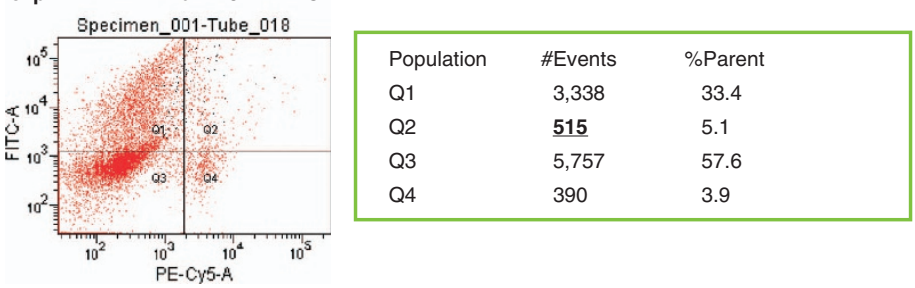

Figure 2 LiCl rescues GFP-exp PABPN (13Ala and 17Ala)-associated cell death. (a) Cell survival determined by live-stage microscopy. C2C12 cells were transfected with a

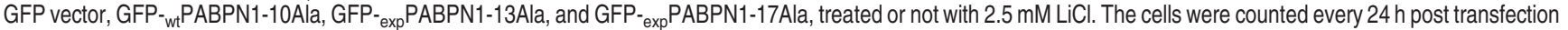
for 6 days consecutively using the live-stage microscope. The percentage of transfected living cells represents the variation of the amount of transfected living cells at different time points compared with the number of transfected cells obtained on day 1. LiCl rescues GFP-exp PABPN1-13Ala and 17Ala-associated cell death ( ${ }^{*} P<0.001$ versus nontreated samples). Mean \pm S.E., ${ }^{*} P<0.05$ compared with any other groups (ANOVA analysis). The experiment was repeated 3 times. (b) Cell death measured by fluorescent flow cytometry (FFC). Percentage of cell death observed by two-color FFC analysis with 7AAD on day 6 post-treatment with 2.5 mM LiCl. GFP-wtPABPN1-10Ala and GFP were used as controls. Cell death was calculated by dividing the number of 7AAD-stained transfected $\mathrm{C} 2 \mathrm{C} 12$ cells over the total number of transfected cells. The experiment was repeated four times. ( ${ }^{*} P<0.001$ versus non-treated samples). (c) A two-color FACS dotplot from a representative experiment in which $\mathrm{C} 2 \mathrm{C} 12$ cells were transfected with GFP-exp PABPN1-17Ala and treated with $2.5 \mathrm{mM} \mathrm{LiCl} \mathrm{(bottom)} \mathrm{compared} \mathrm{with} \mathrm{non-treated} \mathrm{cells} \mathrm{(top),} \mathrm{stained} \mathrm{with} \mathrm{7AAD} \mathrm{to} \mathrm{label} \mathrm{dead} \mathrm{cells,} \mathrm{and} \mathrm{co-sorted} \mathrm{for} \mathrm{GFP} \mathrm{(green)} \mathrm{and}$ 7AAD (red) fluorescence. Grid lines were positioned after calibrating the flow cytometry. Upper right quadrants signify 7AAD-labeled dead or dying transfected cells $\left(\mathrm{GFP}+7 \mathrm{AAD}{ }^{+}\right)$, i.e., Q2 (underlined values)

demonstrate that $\mathrm{LiCl}$ increases the fusion index of cells expressing GFP-exp PABPN1-(13Ala and 17Ala).

LiCl enhances cell survival and differentiation of primary cultures of mouse myoblasts expressing GFP-exp PABPN1 (13Ala and 17Ala). To further confirm the observed protective effects of $\mathrm{LiCl}$ on $\mathrm{C} 2 \mathrm{C} 12$ cells, we assessed both proliferation and differentiation in primary cultures of mouse myoblasts expressing GFP-exp PABPN1 (13Ala and 17Ala) after $\mathrm{LiCl}$ treatment. We followed cell viability using automated live-stage fluorescent microscopy to monitor the number of viable green fluorescent cells over 6 days post transfection. $\mathrm{LiCl}$ treatment showed a consistent and significant protective effect against exp PABPN1-induced cell death, compared with non-treated counterparts. As shown in Figures $5 \mathrm{a}$ and $\mathrm{b}, \mathrm{LiCl}$ increases the survival of cells expressing GFP-exp PABPN1-13Ala and GFP-exp PABPN1-17Ala $\left({ }^{*} P<0.001\right.$ when either transiently expressing $\mathrm{LiCl}$ treated cells are compared with their nontreated counterparts). In addition to enhancing the proliferation of viable cells expressing GFP-expPABPN1-13Ala and GFP-exp PABPN1-17Ala, the drug also enhanced the differentiation of primary myoblast cultures into myotubes (Figures $5 \mathrm{c}$ and d). We also calculated the fusion index of the cultures. The results presented in Figure $5 \mathrm{~d}$ demonstrate that $\mathrm{LiCl}$ increases the fusion index of primary myoblast cells expressing GFP-exp PABPN1 (13Ala and 17Ala). In conclusion, the results we present from primary cultures of mouse myoblasts support the protective effects of $\mathrm{LiCl}$ obtained in the OPMD C2C12 cell model.

$\mathrm{LiCl}$ treatment increases $\beta$-catenin expression and causes it to translocate to the nucleus. The cellular localization of $\beta$-catenin is regulated by its phosphorylation by GSK-3 $\beta$, which lies upstream. In the absence of the Wnt signal, $\beta$-catenin is phosphorylated by GSK- $3 \beta$ and targeted 

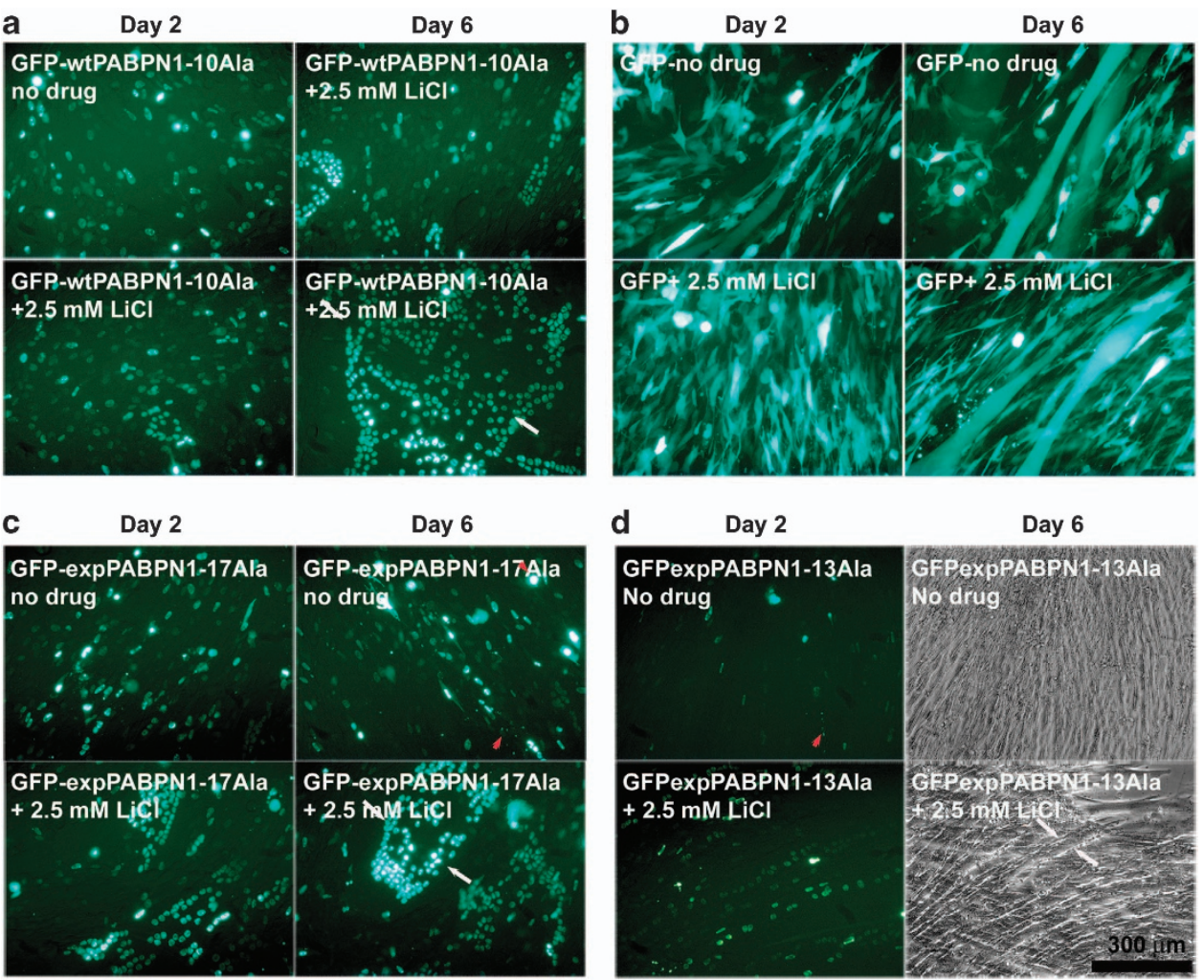

Figure $3 \mathrm{LiCl}$ enhances cell proliferating and differentiation of C2C12 cells transfected with GFP-exp PABPN1-17Ala. (a and $\mathbf{b})$ The effect of LiCl treatment on OPMD C2C12 cell model controls. LiCl maintains the ability of cells expressing GFP-wPABPN1-10Ala (a) and GFP (b) to proliferate and differentiate over the time course. Cells were transiently transfected with GFP- ${ }_{\text {wt }}$ PABPN1-10Ala or GFP and treated with $2.5 \mathrm{mM} \mathrm{LiCl}$ for 6 days in DM. (c) LiCl protects against cell death and enhances the number of multinucleated differentiated myotubes as well as increasing their diameter's size (bottom panels). Cells were transiently transfected with GFP-exp PABPN1-17Ala and treated with $2.5 \mathrm{mM} \mathrm{LiCl}$ for 6 days in DM. Cells were visualized daily under the live-stage microscope for morphology and viability. Representative images were captured on day 2 and day 6 post-treatment with the drug. (d) LiCl enhances muscle differentiation of $\mathrm{C} 2 \mathrm{C} 12$ cells expressing GFP-exp PABPN1-13Ala. Representative images showing the effect of $\mathrm{LiCl}$ on cell differentiation. $\mathrm{LiCl}$ increases the total number of multinucleated myotubes in cells expressing GFP-exp PABPN1-13Ala (bottom left) compared with non-treated GFP-exp PABPN1-13Ala cells (top left). Phase contrast image of myotubes treated with $2.5 \mathrm{mM} \mathrm{LiCl}$ (bottom right) shows the increased diameter size when compared with nontreated cells (top right) on day 6 after differentiation. White arrows point towards the myotube's diameter. Red arrowheads point towards dead cells or debris of dead cells

for degradation by the ubiquitin-proteasome system. Upon Wnt signaling, it cannot be phosphorylated by GSK-3 $\beta$ resulting in its translocation to the nucleus. ${ }^{43} \mathrm{Li}^{+}$ions were in fact shown to inhibit GSK-3 $\beta$ activity, resulting in the elevation of $\beta$-catenin protein levels. ${ }^{44-46}$ Given the protection effect of $\mathrm{LiCl}$ against cell death associated with GFP-exp PABPN1 (13Ala and 17Ala) (Figures 2a and b), we investigated whether $\mathrm{LiCl}$ protected against exp PABPN1associated cell death by upregulating the level of $\beta$-catenin protein. We first analyzed by western blot the transfected cells, which had been treated with $2.5 \mathrm{mM} \mathrm{LiCl}$, and increased expression could be seen in this instance (Figure $6 \mathrm{a}$ ) at $48 \mathrm{~h}$ post transfection; while leaving the level of GFP protein unaffected in cells transfected with GFP-exp PABPN1 (13Ala and 17Ala) (Figure 6b). This suggests that the cell survival protection is mediated through induction of the $\beta$-catenin protein and/or other proteins downstream from $\beta$-catenin rather than affecting the level of PABPN1 protein. The effect of increasing the $\mathrm{LiCl}$ concentration on enhancing $\beta$-catenin level was also studied in non-transfected $\mathrm{C} 2 \mathrm{C} 12$ cells (Supplementary Figure S1). Using immunocytochemistry, we then examined the subcellular localization of $\beta$-catenin in cells and compared it before and after a $\mathrm{LiCl}$ treatment. In the absence of $\mathrm{LiCl}$ treatment, expression of $\beta$-catenin appears cytoplasmic (Figures $6 \mathrm{c}$ and $\mathrm{d}$, left panels). But following treatment with $\mathrm{LiCl}$, a clear nuclear accumulation of $\beta$-catenin can be observed in cells expressing GFP- ${ }_{\text {wt }}$ PABPN1-10Ala and GFP-exp PABPN1-17Ala, respectively (Figures $6 \mathrm{c}$ and $\mathrm{d}$, right panels). Figures $6 c$ and d show that treatment with $\mathrm{LiCl}$ leads to a significant nuclear translocation of $\beta$-catenin from the cytoplasm to the nuclear compartment in both cells transfected with GFP-wt ${ }_{\text {PABPN1-10Ala and GFP-exp } P A B P N 1-17 A l a,}$ respectively. Thus, we conclude that $\mathrm{LiCl}$ could activate a pro-survival pathway in the $\mathrm{C} 2 \mathrm{C} 12$ OPMD model through activation of the $\beta$-catenin protein.

Similar expression of $\beta$-catenin in OPMD and control lymphoblastoid cell lines. To investigate whether $\mathrm{Wnt} / \beta$ catenin signaling pathway is implicated in OPMD pathogenesis, we first investigated the level of endogenous $\beta$-catenin from OPMD lymphoblastoid cell lines and compared it with that of control LCLs. As shown in Figure 7a, no clear difference was detected in the protein level of $\beta$-catenin from OPMD LCLs compared with controls. We then performed immunocytochemistry to examine if the distribution of 


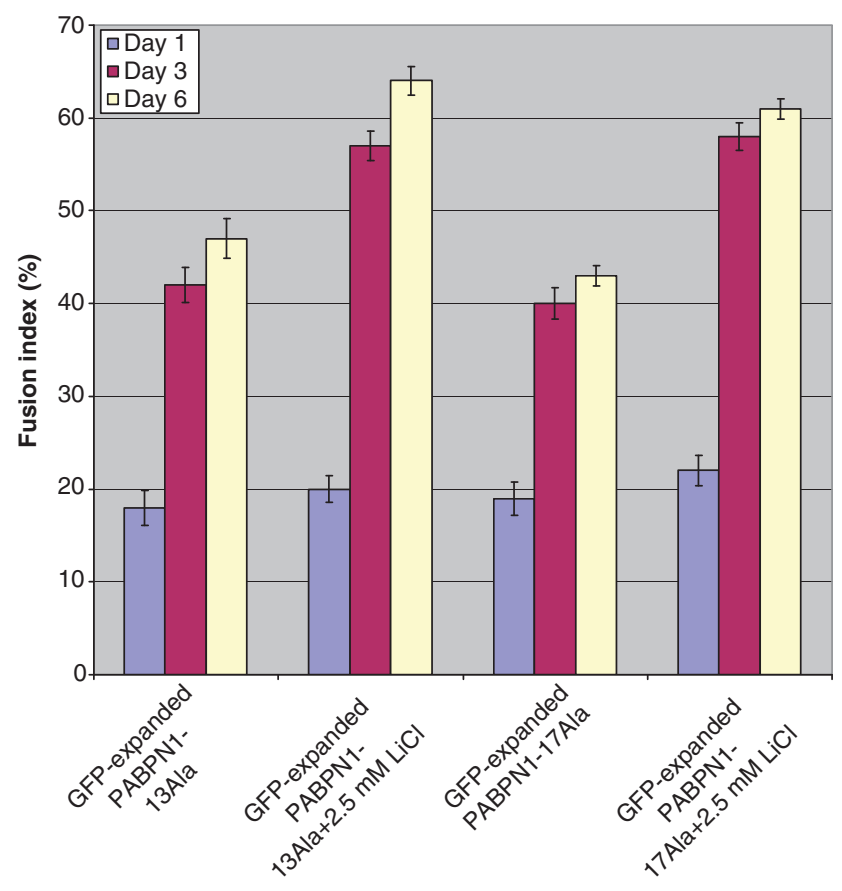

Figure $4 \mathrm{LiCl}$ enhances muscle differentiation of $\mathrm{C} 2 \mathrm{C} 12$ cells expressing GFP-exp PABPN1-13Ala and 17Ala. LiCl increases the differentiation index of C2C12 cells expressing GFP-exp PABPN1 (13Ala and 17Ala). The histogram represents the fusion index calculated at the indicated times after the addition of DM for cells expressing GFP-exp PABPN1-13Ala and GFP-exp PABPN1-17Ala treated or not treated with $2.5 \mathrm{mM}$ LiCl. Myogenic index was determined as the ratio of the nuclei number of cells containing two or more nuclei to the total nuclei number of desmin $\mathrm{C} 2 \mathrm{C} 12$-stained myotubes. The number of nuclei within each individual myotube was counted for 100-150 myotubes per well. At least three different fields containing 100 cells were counted. Data are the mean \pm S.E. of three independent experiments

$\beta$-catenin in patient OPMD LCLs is different from control LCLs. As shown in Figure $7 \mathrm{~b}$, the subcellular distribution of $\beta$-catenin was similar in both the OPMD patient and control LCLs (Figure 7b). The expression of $\beta$-catenin is uniformly distributed within the cytoplasm and nucleus in both the OPMD patient and control LCLs (Figure 7b).

The $\beta$-catenin protein level is increased in OPMD LCL upon treatment with $\mathrm{LiCl}$. We were interested to see whether the effect of $\mathrm{LiCl}$ on LCLs from OPMD patients would be similar to what could be seen in our C2C12 OPMD model. The reason for this is that the expression of exp PABPN1 in these LCLs is more likely to be closer to the endogenous levels seen in OPMD patients, in comparison with the level of expression observed in transfected $\mathrm{C} 2 \mathrm{C} 12$ cells. For that reason, we looked if the $\beta$-catenin level could be induced in OPMD LCLs following their incubation with $2.5 \mathrm{mM} \mathrm{LiCl}$ for $48 \mathrm{~h}$. $\mathrm{LiCl}$ was indeed able to increase the level of $\beta$-catenin in OPMD LCLs as detected by western blot (Figure 7c).

\section{Discussion}

Drug discovery for late-onset diseases like OPMD is a major challenge. In large part, the complexity of treating these disorders results from our insufficient understanding of the contributions of multiple pathways to disease pathophysiology.

Evidence has been accumulated showing preclinical efficacy for GSK- $\beta$ inhibitors in very different models of several distinct pathologies. These drugs offer promising examples of new therapies for diabetes, cancer, inflammation, Alzheimer's disease, polyglutamine diseases, and mood disorders. ${ }^{33}$ Lithium was the first GSK-3 $\beta$ inhibitor discovered. ${ }^{4-49}$ Lithium is highly effective in the treatment of bipolar disorder and also has multiple effects on embryonic development, glycogen synthesis, hematopoiesis, and other processes. ${ }^{49}$ Agents such as lithium that inhibit GSK-3 $\beta$ are predicted to mimic Wnt signaling, ${ }^{47}$ and this has been observed in numerous settings; lithium leads to accumulation and nuclear localization of $\beta$-catenin protein in different models. It is important to note that $\mathrm{LiCl}$ might be responsible for inhibitory events other than the GSK- $3 \beta .^{50}$ Our results, here, indicate that $\mathrm{LiCl}$ is likely to protect at much lower doses in OPMD compared with the higher doses used in psychiatric diseases. This would avoid unwanted toxic effects associated with high doses.

Our data show that $\mathrm{LiCl}$ protects against exp PABPN1 and its polyalanine expansion-associated death in murine $\mathrm{C} 2 \mathrm{C} 12$ myoblast cells. These protective effects are likely to be mediated by $\beta$-catenin, at least in part, as $\mathrm{LiCl}$ enhances the expression of $\beta$-catenin in our C2C12 OPMD cell model. Moreover, given $\mathrm{LiCl}$ also enhances the expression of $\beta$-catenin in OPMD patients' LCLs, we reason that the expression of exp PABPN1 is not an upstream effector of $\beta$-catenin; the level of expression of exp PABPN1 in $\mathrm{C} 2 \mathrm{C} 12$ transiently expressing the transgene is probably higher than what can be seen in OPMD patients' LCLs expressing exp PABPN1. The protective effect of $\mathrm{LiCl}$ at concentrations mimicking what would be seen at therapeutic doses in vivo suggests that this drug needs serious consideration for therapeutic trials using the previously reported OPMD mouse models. $^{9}$

It was interesting to find out that $\mathrm{LiCl}$-reduced cell death caused by the OPMD mutation without reducing the proportion of cells with aggregates. This is in agreement with our previous study suggesting that aggregates could be protective to the disease rather than causative. ${ }^{40}$ Our earlier studies on worm muscle cells have also shown that early phases of soluble expPABPN1 contribute to OPMD-associated toxicity. ${ }^{12,34}$ Many reports indicate that the Wnt signaling pathway regulates apoptosis through a variety of mechanisms. ${ }^{51}$ Lithium treatment enhances the expression of cell survival genes like $b c l-2, H s p 70, \beta$-catenin, BDNF, and CREB.$^{52-54}$ Here, we report that $\beta$-catenin appears to be a critical factor for the $\mathrm{LiCl}-d e p e n d e n t$ protection of GFP-exp PABPN1-associated cell death.

Our results indicate a positive effect of $\mathrm{LiCl}$ on muscle cell differentiation. The Wnt signaling pathway has been shown to have a strong effect on cell proliferation and survival and it may contribute to the overall process of myogenesis. ${ }^{55} \mathrm{Wnt}$ signaling directs cell fate determination in various tissues, including skeletal muscle. ${ }^{55} \mathrm{~A}$ report by Polesskaya et $a^{56}$ showed that Wnt signaling induces the myogenic specification of resident CD45 + adult stem cells during muscle regeneration. ${ }^{56}$ This observation suggests that the 

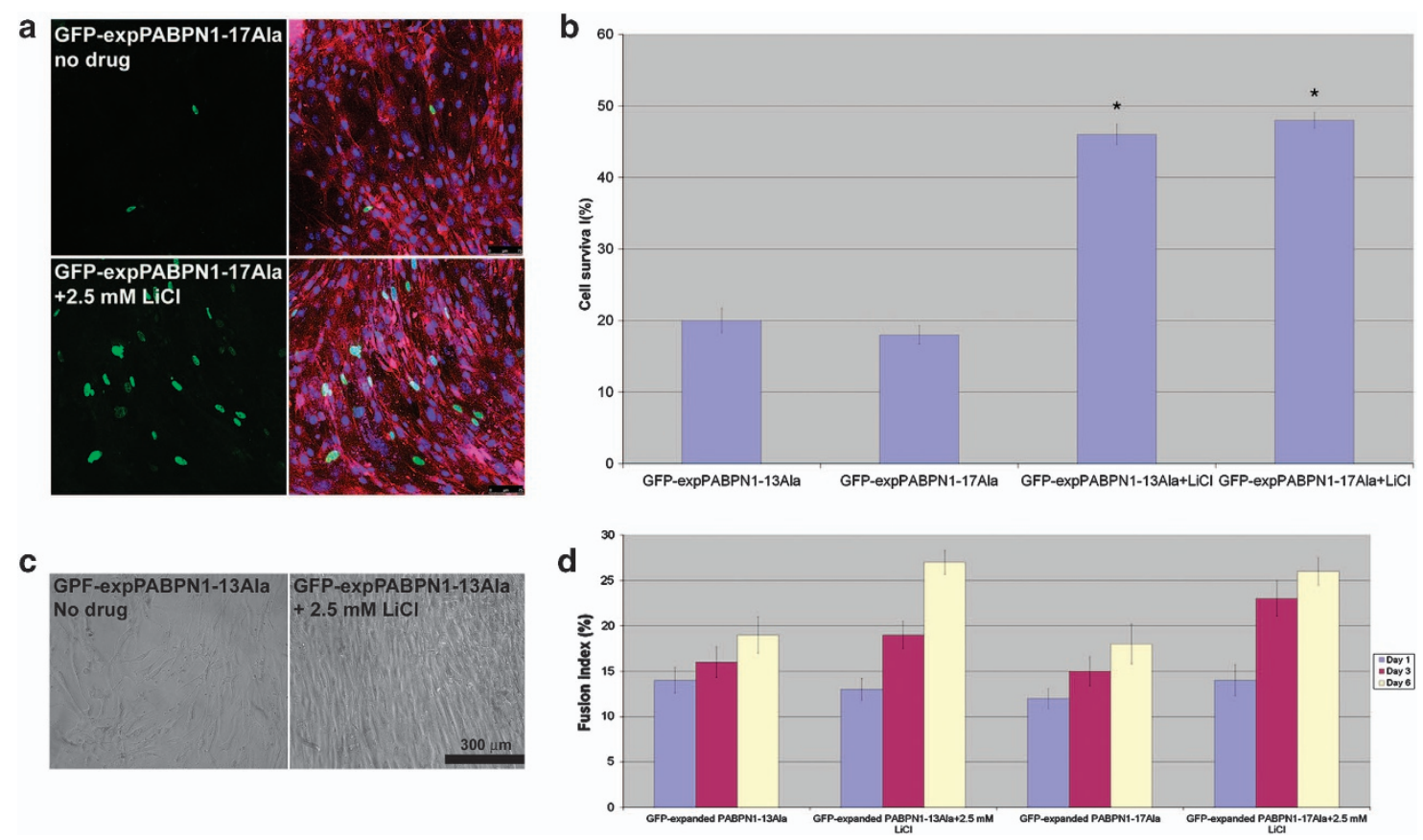

Figure $5 \mathrm{LiCl}$ increases cell survival and differentiation of primary cultures of mouse myoblasts expressing GFP-exp PABPN1 (13Ala and 17Ala). (a) Cell survival determined by live-stage microscopy. Confocal images showing the presence of an increased number of green cells (GFP-exp PABPN1-17Ala) following a treatment (2.5 mM $\mathrm{LiCl}$, bottom) support their increased survival by comparison with what is observed when the same cells were not treated with $\mathrm{LiCl}$ (top). Immnocytochemistry images were taken at day 6 post-transfection. GFP- ${ }_{\text {exp }}$ PABPN1-17Ala (green), desmin (red), and DAPI (blue). (b) LiCl increases the number of viable cells. Primary cultures mouse myoblasts expressing GFP-exp PABPN1-13Ala, and GF-exp PABPN1-17Ala, treated or not with $2.5 \mathrm{mM} \mathrm{LiCl}$ were counted at day 6 post-transfection using the live-stage microscope. Three different fields were chosen and cells were counted. Mean \pm S.E., ${ }^{*} P<0.05$ compared with any other groups (ANOVA analysis). The experiment was repeated three times. (c) LiCl enhances muscle differentiation of primary mouse myoblasts expressing GFP-exp PABPN1-13Ala. Representative images showing the effect of $\mathrm{LiCl}$ on cell differentiation. Phase contrast images of myotubes treated with $2.5 \mathrm{mM} \mathrm{LiCl}$ (right) show an increased number of many elongated myotubes compared with non-treated cells (left) on day 6 after differentiation. (d) LiCl increases the differentiation index of primary mouse myoblast cells expressing GFP-exp PABPN1 (13Ala and 17Ala). The histogram represents the fusion index calculated at the indicated times after DM addition for cells expressing GFP-exp PABPN1-13Ala and GFP-exp PABPN1-17Ala treated or not with $2.5 \mathrm{mM} \mathrm{LiCl}$. At least three different fields containing 100 cells were counted. Data are the mean \pm S.E. of three independent experiments

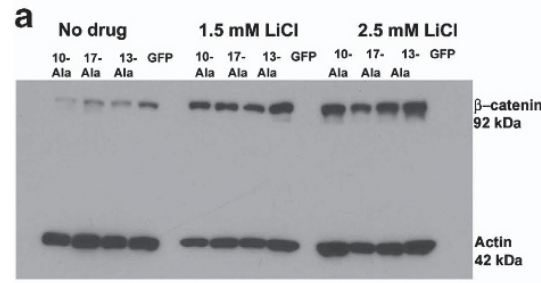

C

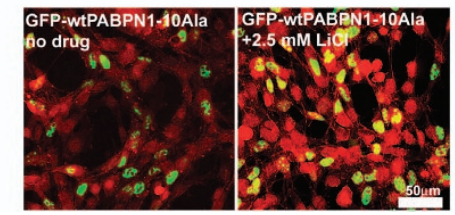

b No Drug

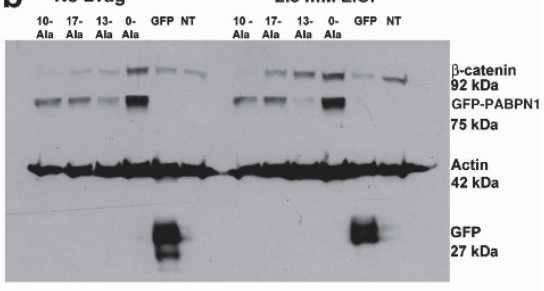

d

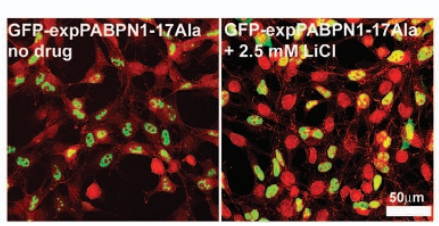

Figure $6 \mathrm{LiCl}$ leads to a significant increase of the $\beta$-catenin level in the OPMD C2C12 cell model. (a and $\mathbf{b})$ LiCl leads to a significant increase of $\beta$-catenin in the OPMD $\mathrm{C} 2 \mathrm{C} 12$ cell model while leaving the GFP level not affected. A western blot showing the effect of $\mathrm{LiCl}$ treatment on the $\beta$-catenin level at $48 \mathrm{~h}$ post transfection. $\mathrm{C} 2 \mathrm{C} 12 \mathrm{myoblast}$ cells were transiently transfected with different PABPN1 constructs as well as GFP, and non-transfected cells, and treated or not with two different doses of LiCl as indicated. Actin antibody was used to confirm equal loading. (c and $\mathbf{d}$ ) LiCl treatment results in re-distribution of $\beta$-catenin from a cytoplasmic to a nuclear compartment. Confocal images of immunocytochemistry showing the subcellular distribution of $\beta$-catenin. A clear accumulation of $\beta$-catenin in the nucleus was observed in the C2C12-transfected cells with GFP-witPABPN1-10Ala (c) and GFP-exp PABPN1-17Ala (d) after LiCl treatment. GFP-PABPN1 constructs (green), $\beta$-catenin (red)

Wnt pathway might represent a promising therapeutic target for degenerative neuromuscular diseases like OPMD. Other reports have also indicated an involvement of the Wnt pathway in crucial aspects of synaptic development, particularly at the level of the neuromuscular junction. ${ }^{57}$ Inhibition of glycogen synthase kinase- $3 \beta$ has been shown to play a role in 

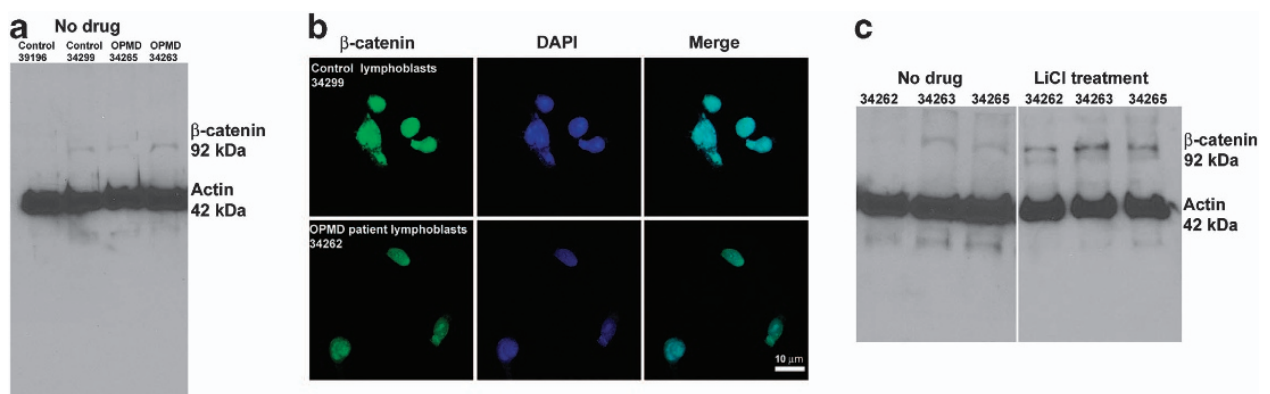

Figure 7 Increased level of $\beta$-catenin protein in the OPMD patient LCLs upon LiCl treatment. (a and $\mathbf{b}$ ) show no difference in the $\beta$-catenin level between OPMD and control LCLs. (a) A Western blot of proteins extracted from controls and OPMD LCLs and detected with the $\beta$-catenin antibody. Actin is used as a control for equal loading of protein. The two control LCLs are: 39196 and 34 299. The two patient OPMD LCLs are: 34265 and 34 263. (b) Confocal images showing similar distribution of $\beta$-catenin protein in both control and patient OPMD LCLs. Immunofluorescent images of LCLs from control 34299 (top panels) and patient 34262 (bottom panel) were detected using the $\beta$-catenin antibody (green). TOTO (blue) stains for the nucleus. LCLs from control and OPMD patient are 34299 and 34 262, respectively. (c) The western blot shows increased level of $\beta$-catenin protein after $48 \mathrm{~h}$ of LiCl treatment. The numbers refer to different OPMD LCLs. Actin was used to confirm equal loading of protein

stimulating myogenic differentiation, ${ }^{58,59}$ as well as a possible treatment for sporadic inclusion-body myositis myopathy. ${ }^{60}$

In conclusion, we find that $\mathrm{LiCl}$ rescues polyalanine expansion-associated cell death in our C2C12 OPMD cell model and in primary cultures of mouse myoblasts expressing exp PABPN1. This protection is mediated by increases in $\beta$-catenin and muscle cell differentiation. As LiCl, a commonly used drug, can protect against OPMD-associated cell death, it is an excellent candidate for further in vivo therapeutic trials.

\section{Materials and Methods \\ Plasmid constructs. The cDNAs encoding wild-type PABPN1 with 10 alanines and expanded PABPN1 with 13 and 17 alanines (the most common mutation seen in patients) were cloned into the pEGFP-C2 vector (Clontech, Palo Alto, CA, USA) to create N-terminal GFP-fusion GFP at of PABPN1 proteins (GFP-wPABPN1-10Ala, GFP-exp PABPN1-13Ala and GFP-exp PABPN1-17Ala). The DNA sequence of every GFP-tagged transgene was verified using Sanger sequencing.}

Cell culture and transfection. Twenty-four hours before transfection, C2C12 cells were seeded in Dulbecco's modified Eagle's medium (DMEM) containing $20 \%$ fetal calf serum at a concentration of $2 \times 10^{5}$ cells per well in 12-well plates suited for automated live microscopy. The cells were transfected with plasmid DNA $(1 \mu \mathrm{g})$ pre-complexed with the Plus reagent and diluted in Lipofectamine reagent (Invitrogen, Burlington, ON, Canada) according to the manufacturer's instructions. To check protein expression before and after the drug treatment, parallel plates were prepared for western blot. When cultivated in growth media (GM), which is DMEM containing $10 \%$ fetal bovine serum, proliferating $\mathrm{C} 2 \mathrm{C} 12$ cells grow as mononucleated flattened cells in a monolayer. When confluent cells were incubated in differentiation media (DM) which is DMEM containing $2 \%$ horse serum, the majority of $\mathrm{C} 2 \mathrm{C} 12$ cells assumed elongated morphology and fused to become multinucleated myotubes or myocytes.

Primary culture of mouse myoblasts. Primary myoblasts were derived from the hindlimb of neonatal 2 day old mouse pups and cultured to $0.99 \%$ purity as previously described (56). Cells were maintained in growth media (GM: Ham's $\mathrm{F} 10,20 \% \mathrm{FBS}, 5 \mathrm{ng} / \mathrm{ml} \mathrm{bFGF}, 100 \mathrm{U} / \mathrm{ml}$ penicillin G, $100 \mathrm{mg} / \mathrm{ml}$ streptomycin) in a humidified $5 \% \mathrm{CO} 2$ incubator at $37^{\circ} \mathrm{C}$ on collagen coated dishes. To induce differentiation, cells were plated on culture slides coated with Collagen type 1 (BD BioCoat, BD Biosciences, Mississauga, ON, Canada) in GM and shortly thereafter switched to differentiation media (DM:DMEM, $2 \%$ horse serum (Invitrogen), $100 \mathrm{U} / \mathrm{ml}$ penicillin and $100 \mathrm{mg} / \mathrm{ml}$ streptomycin) for the indicated times. For transfection, Jet Prime reagent was used according to the manufacturer's protocol (Polyplus Transfection, New York, NY, USA). All experiments were analyzed at least three times independently.

Measurement of myogenic index. For differentiation studies, cells were seeded at confluence on the film surface. The samples were cultured in expansion medium for $24 \mathrm{~h}$, after which the medium was replaced with DM. The myogenic index was determined as the ratio of the nuclei number in the cells containing two or more nuclei to the total nuclei number in desmin stained myotubes of $\mathrm{C} 2 \mathrm{C} 12$ cells. The number of nuclei within each individual myotube was counted for 100-150 myotubes per well. At least three different fields containing 100 cells were counted. Data are the mean \pm S.E. of three independent experiments.

Human Lymphoblastoid Cells (LCLs) cultures. LCLs were established from peripheral blood samples. Cells were maintained in RPMI 1640 with $2 \mathrm{mM} \mathrm{L}$-glutamine and $10 \% \mathrm{FBS}$ in a $37^{\circ} \mathrm{C}$ incubator (5\% CO2). Control LCLs used in this study are: 39196 and 34 299. Patient OPMD LCLs used in this study are 34262,34263 , and 34265 .

LiCl treatment. LiCl (Sigma, Oakville, ON, Canada) was dissolved in water. In the initial cell treatment experiments, we performed dose-response experiments on the non-transfected cells, to establish the best concentration for subsequent tests. $\mathrm{LiCl}(2.5 \mathrm{mM})$ was the most appropriate dose, as it did not cause cell toxicity for the period of experiments, and therefore was used throughout the experiments described below. $\mathrm{LiCl}$ was applied 3 days before transfection, and continued to be administered to the transfected cells every $24 \mathrm{~h}$. Controls where no drug was applied to the transfected cells were also included. Cells (in 12-well plate) were then incubated in a cell culture incubator $\left(5 \% \mathrm{CO}_{2}\right)$ for $24 \mathrm{~h}$ before either placing them on a Leica DMI 6000 (Concord, ON, Canada) automated live-stage microscope, or preparing the proteins for other experiments.

Western blotting. Proteins were extracted, separated by SDS-PAGE and analyzed by western immunodetection using the following primary antibodies: mouse anti-GFP (Clontech, 1:2000), rabbit $\beta$-catenin (Cell Signaling, Whitby, ON, Canada, $1: 1000$ ), and mouse anti-actin (Invitrogen, $1: 2000$ ). The membranes were detected using the western Blot Chemiluminescence reagent Plus kit (NEN Life Science Products, Boston, MA, USA). Parallel samples were probed using an anti-actin antibody (Chemicon, Billerica, MA, USA) to confirm the equal loading of lysates between lanes.

Assessment of protein expression and cell survival using the automated microscope. A 12-well plate containing transfected cells (GFP- ${ }_{\text {wi }}$ PABPN1-10Ala, GFP-exp PABPN1-13Ala, GFP-exp PABPN1-17Ala, and GFP as well as non-transfected cells) treated or not with $\mathrm{LiCl}$ was placed on a Leica automated microscope stage, connected to Volocity software (PerkinElmer Improvision, Montreal, $\mathrm{QC}$, Canada); the microscope is equipped with digital camera, $\mathrm{CO}_{2}$ incubation chamber, and an electronically controlled motorized $x y$ axis stage. Cells could be monitored over a long period of time for expressing the fluorescent marker. The microscopic robotic stage allows parallel tracking of multiple fields, both within a single well and in multiple wells. We programmed Volocity software to keep track of three different fields/well containing cells, and programmed the stage to return to the same position at pre-fixed time intervals over the 6 days post transfection and post-treatment with LiCl. 
We monitored cell survival by counting the cells every $24 \mathrm{~h}$ for 6 days continuously. Day 1 indicates $24 \mathrm{~h}$ post transfection. The percentage of living transfected cells represents the variation of the amount of living transfected cells at different time points compared with the number of transfected cells obtained on day 1. On average, around 150 cells from each field for each construct were counted Cell viability was assessed by analysis of GFP-positive cells. GFP-expressing cells with fragmented or condensed nuclei were counted as dead. In addition to green images, we also recorded the phase images to get a clear idea about the status of the cells (e.g., healthy, dead) and to confirm the healthy GFP cells counting. Average cell survival of each group of cells was scored for the three different chosen fields. The experiments were repeated three times. All values were expressed as means \pm S.E. ${ }^{*} P<0.05$ compared with any other groups (ANOVA analysis). The experiment was repeated three times.

Assessment of cell survival using FFC. C2C12 cells were seeded into six-well culture plates $\left(2 \times 10^{5}\right.$ cells/well). Twenty-four hours later cells were transfected with plasmids encoding GFP, or GFP-wtPABPN-10Ala, or GFP-exp $P A B P N 1-13$ Ala and 17Ala. Non-transfected cells were used as controls throughout the study. The cells were pretreated with $2.5 \mathrm{mM} \mathrm{LiCl}$ for 3 days before transfection. Treated transfected cells were collected at different days (day 1-day 6 post transfection) and resuspended in $100 \mu \mathrm{l}$ of FACS buffer (PBS-containing 1\% FBS and 0.1 sodium azide) containing $50 \mu \mathrm{M}$ with 7-aminoactinomycin $D(7 A A D)$. Labeled cells were sorted by fluorescence using a BD Flow Cytometer (BD Biosciences) and a minimum of 10000 events were recorded per sample using BD FACSDiva Software (BD Biosciences). Before each experiment, the flow cytometer was calibrated using three control groups: unstained cells to gate autofluorescence, cells expressing GFP without 7AAD, and cells treated with DMSO to induce cell death having been stained with 7AAD. Using FACSDiva Software, data were displayed in a four quadrant dotplot format on a log-scale. The cell death was expressed as a percentage by dividing the number of transfected cells that stained with 7AAD (green and red) by the total number of transfected cells. Cell death percentages were normalized to that of non-transfected cells.

Immunocytochemistry. Seventy two hours after transfection and drug treatment, cells were washed with PBS, fixed for 15 min with $4 \%$ paraformalde hyde, permeabilized for $5 \mathrm{~min}$ with $0.05 \%$ Triton-X/PBS, then blocked with $10 \%$ normal goat serum (NGS)/PBS. Cells were incubated overnight in primary antibody in the following dilutions: $\alpha \beta$-catenin $=1: 200$ (Cell Signaling) in $2 \%$ NGS/PBS, $\alpha$ desmin $=1: 100$ (Cedarlane, Burlington, ON, Canada). For fluorescent detection experiments, cells were incubated in the appropriate secondary fluorescent antibody (Alex 488, 1: 1000), washed, and then mounted in Moviol (Fluka, Oakville, ON, Canada). Cells were visualized using appropriate filters on a Leica DMI 6000 microscope.

Statistical analysis. All values represent the mean of at least three independent experiments (mean \pm S.E.M.). Statistical significance was determined by one-way ANOVA. $P$-values $<0.05$ were designated as statistically significant.

\section{Conflict of Interest}

The authors declare no conflict of interest.

Acknowledgements. We thank Dr. Masoud Shekarabi for his assistance with the manuscript's revision. We would like to thank Genevieve Castonguay for excellent technical assistance. This work was supported by the Muscular Dystrophy Association (MDA), the Canadian Institute of Health Research, and the Federation Foundation of Greater Philadelphia.

1. Dion P, Shanmugam V, Gaspar C, Messaed C, Meijer I, Toulouse A et al. Transgenic expression of an expanded (GCG)13 repeat PABPN1 leads to weakness and coordination defects in mice. Neurobiol Dis 2005; 18: 528-536.

2. Boukriche $Y$, Maisonobe $T$, Masson $C$. Neurogenic involvement in a case of oculopharyngeal muscular dystrophy. Muscle Nerve 2002; 25: 98-101.

3. Schober R, Kress W, Grahmann F, Kellermann S, Baum P, Gunzel S et al. Unusual triplet expansion associated with neurogenic changes in a family with oculopharyngeal muscular dystrophy. Neuropathology 2001; 21: 45-52.

4. Brais B, Rouleau GA, Bouchard JP, Fardeau M, Tome FM. Oculopharyngeal muscular dystrophy. Semin Neurol 1999; 19: 59-66.
5. Brais B, Bouchard JP, Xie YG, Rochefort DL, Chretien N, Tome FM et al. Short GCG expansions in the PABP2 gene cause oculopharyngeal muscular dystrophy. Nat Genet 1998; 18: 164-167.

6. Abu-Baker A, Messaed C, Laganiere J, Gaspar C, Brais B, Rouleau GA. Involvement of the ubiquitin-proteasome pathway and molecular chaperones in oculopharyngeal muscular dystrophy. Hum Mol Genet 2003; 12: 2609-2623.

7. Bao YP, Cook LJ, O'Donovan D, Uyama E, Rubinsztein DC. Mammalian, yeast, bacterial, and chemical chaperones reduce aggregate formation and death in a cell model of oculopharyngeal muscular dystrophy. J Biol Chem 2002; 277: 12263-12269.

8. Wang Q, Mosser DD, Bag J. Induction of HSP70 expression and recruitment of HSC70 and HSP70 in the nucleus reduce aggregation of a polyalanine expansion mutant of PABPN1 in HeLa cells. Hum Mol Genet 2005; 14: 3673-3684.

9. Davies JE, Wang L, Garcia-Oroz L, Cook LJ, Vacher C, O'Donovan DG et al. Doxycycline attenuates and delays toxicity of the oculopharyngeal muscular dystrophy mutation in transgenic mice. Nat Med 2005; 11: 672-677.

10. Chartier A, Raz V, Sterrenburg E, Verrips CT, van der Maarel SM, Simonelig M. Prevention of oculopharyngeal muscular dystrophy by muscular expression of Llama single-chain intrabodies in vivo. Hum Mol Genet 2009; 18: 1849-1859.

11. Davies JE, Rose C, Sarkar S, Rubinsztein DC. Cystamine suppresses polyalanine toxicity in a mouse model of oculopharyngeal muscular dystrophy. Sci Trans/ Med 2010; 2: 34ra40.

12. Catoire H, Pasco MY, Abu-Baker A, Holbert S, Tourette C, Brais B et al. Sirtuin inhibition protects from the polyalanine muscular dystrophy protein PABPN1. Hum Mol Genet 2008; 17: 2108-2117.

13. Clevers H, Nusse R. Wnt/beta-catenin signaling and disease. Cell 2012; 149: 1192-1205.

14. Clevers H. Wnt/beta-catenin signaling in development and disease. Cell 2006; 127: $469-480$

15. Logan CY, Nusse R. The Wnt signaling pathway in development and disease. Annu Rev Cell Dev Biol 2004; 20: 781-810.

16. Moon RT, Kohn AD, De Ferrari GV, Kaykas A. WNT and beta-catenin signalling: diseases and therapies. Nat Rev Genet 2004; 5: 691-701.

17. Clevers $\mathrm{H}$, Batlle $\mathrm{E}$. EphB/EphrinB receptors and Wnt signaling in colorectal cancer. Cancer Res 2006; 66: 2-5.

18. Lawrence PA, Struhl G, Casal J. Planar cell polarity: one or two pathways? Nat Rev Genet 2007; 8: 555-563.

19. Kuhl M, Sheldahl LC, Park M, Miller JR, Moon RT. The Wnt/Ca2 + pathway: a new vertebrate Wnt signaling pathway takes shape. Trends Genet 2000; 16: 279-283.

20. MacDonald BT, Tamai K, He X. Wnt/beta-catenin signaling: components, mechanisms, and diseases. Dev Cell 2009; 17: 9-26.

21. Ben-Ze'ev A. Cytoskeletal and adhesion proteins as tumor suppressors. Curr Opin Cell Biol 1997; 9: 99-108

22. Ben-Ze'ev A, Geiger B. Differential molecular interactions of beta-catenin and plakoglobin in adhesion, signaling and cancer. Curr Opin Cell Biol 1998; 10: 629-639.

23. Bullions LC, Levine AJ. The role of beta-catenin in cell adhesion, signal transduction, and cancer. Curr Opin Oncol 1998; 10: 81-87.

24. Willert K, Nusse R. Beta-catenin: a key mediator of Wnt signaling. Curr Opin Genet Dev 1998; 8: 95-102

25. Semenov MV, Habas R, Macdonald BT, He X. SnapShot: noncanonical Wnt signaling pathways. Cell 2007; 131: 1378.

26. Dierick H. Bejsovec A. Cellular mechanisms of wingless/Wnt signal transduction. Curr Top Dev Biol 1999; 43: 153-190

27. Wodarz A, Nusse R. Mechanisms of Wnt signaling in development. Annu Rev Cell Dev Biol 1998; 14: 59-88.

28. Meijer L, Skaltsounis AL, Magiatis P, Polychronopoulos P, Knockaert M, Leost M et al. GSK-3-selective inhibitors derived from Tyrian purple indirubins. Chem Biol 2003; 10: 1255-1266.

29. Kleber M, Sommer L. Wnt signaling and the regulation of stem cell function. Curr Opin Cell Biol 2004; 16: 681-687.

30. Eldar-Finkelman $\mathrm{H}$. Glycogen synthase kinase 3: an emerging therapeutic target. Trends Mol Med 2002; 8: 126-132.

31. Woodgett JR. Judging a protein by more than its name: GSK-3. SCi STKE 2001; 2001: re12.

32. Frame $\mathrm{S}$, Cohen P. GSK3 takes centre stage more than 20 years after its discovery. Biochem J 2001; 359(Pt 1): 1-16.

33. Martinez A, Castro A, Dorronsoro I, Alonso M. Glycogen synthase kinase 3 (GSK-3) inhibitors as new promising drugs for diabetes, neurodegeneration, cancer, and inflammation. Med Res Rev 2002; 22: 373-384.

34. Pasco MY, Catoire H, Parker JA, Brais B, Rouleau GA, Neri C. Cross-talk between canonical Wnt signaling and the sirtuin-FoxO longevity pathway to protect against muscular pathology induced by mutant PABPN1 expression in C. elegans. Neurobiol Dis 38: 425-433.

35. Freeman MP, Freeman SA. Lithium: clinical considerations in internal medicine. Am J Med 2006; 119: 478-481.

36. Dubovsky SL. Treatment of bipolar depression. Psychiatr Clin North Am 2005; 28. 349-370, vii.

37. Cohen P, Yellowlees D, Aitken A, Donella-Deana A, Hemmings BA, Parker PJ. Separation and characterisation of glycogen synthase kinase 3 , glycogen synthase kinase 4 and glycogen synthase kinase 5 from rabbit skeletal muscle. Eur J Biochem 1982; 124: 21-35.

38. Woodgett JR. Molecular cloning and expression of glycogen synthase kinase-3/factor A. EMBO J 1990; 9: 2431-2438. 
39. Nonaka S, Chuang DM. Neuroprotective effects of chronic lithium on focal cerebral ischemia in rats. Neuroreport 1998; 9: 2081-2084.

40. Messaed C, Dion PA, Abu-Baker A, Rochefort D, Laganiere J, Brais B et al. Soluble expanded PABPN1 promotes cell death in oculopharyngeal muscular dystrophy. Neurobiol Dis 2007; 26: 546-557.

41. Chalfie M, Tu Y, Euskirchen G, Ward WW, Prasher DC. Green fluorescent protein as a marker for gene expression. Science 1994; 263: 802-805.

42. Heim R, Cubitt AB, Tsien RY. Improved green fluorescence. Nature 1995; 373: 663-664.

43. Gumbiner BM. Carcinogenesis: a balance between beta-catenin and APC. Curr Biol 1997; 7: R443-R446.

44. Stambolic V, Ruel L, Woodgett JR. Lithium inhibits glycogen synthase kinase- 3 activity and mimics wingless signalling in intact cells. Curr Biol 1996; 6: 1664-1668.

45. Aberle H, Bauer A, Stappert J, Kispert A, Kemler R. Beta-catenin is a target for the ubiquitin-proteasome pathway. EMBO J 1997; 16: 3797-3804.

46. Orford K, Crockett C, Jensen JP, Weissman AM, Byers SW. Serine phosphorylationregulated ubiquitination and degradation of beta-catenin. J Biol Chem 1997; 272 24735-24738.

47. Klein PS, Melton DA. A molecular mechanism for the effect of lithium on development. Proc Natl Acad Sci USA 1996; 93: 8455-8459.

48. Cade JF. Lithium salts in the treatment of psychotic excitement. Med J Aust 1949; 2: 349-352.

49. Phiel CJ, Klein PS. Molecular targets of lithium action. Annu Rev Pharmacol Toxicol 2001; 41: 789-813.

50. Hedgepeth CM, Conrad LJ, Zhang J, Huang HC, Lee VM, Klein PS. Activation of the Wnt signaling pathway: a molecular mechanism for lithium action. Dev Biol 1997; 185: 82-91.

51. Pecina-Slaus N. Wnt signal transduction pathway and apoptosis: a review. Cancer Cell Int 2010; 10: 22.

52. Sadoul R. Bcl-2 family members in the development and degenerative pathologies of the nervous system. Cell Death Differ 1998; 5: 805-815.
53. Chuang DM. Neuroprotective and neurotrophic actions of the mood stabilizer lithium: can it be used to treat neurodegenerative diseases? Crit Rev Neurobiol 2004; 16: 83-90.

54. Adams JM, Cory S. The Bcl-2 protein family: arbiters of cell survival. Science 1998; 281 1322-1326.

55. Cossu G, Borello U. Wnt signaling and the activation of myogenesis in mammals. EMBO J 1999; 18: 6867-6872.

56. Polesskaya A, Seale $P$, Rudnicki MA. Wnt signaling induces the myogenic specification of resident $C D 45+$ adult stem cells during muscle regeneration. Cell 2003; 113: 841-852.

57. Korkut C, Budnik V. WNTs tune up the neuromuscular junction. Nat Rev Neurosci 2009; 10: $627-634$.

58. Verhees KJ, Schols AM, Kelders MC, Op den Kamp CM, van der Velden JL, Langen RC Glycogen synthase kinase-3beta is required for the induction of skeletal muscle atrophy. Am J Physiol Cell Physiol 2011; 301: C995-C1007.

59. van der Velden JL, Langen RC, Kelders MC, Wouters EF, Janssen-Heininger YM, Schols AM. Inhibition of glycogen synthase kinase-3 beta activity is sufficient to stimulate myogenic differentiation. Am J Physiol Cell Physiol 2006; 290: C453-C462.

60. Terracciano C, Nogalska A, Engel WK, Askanas V. In A beta PP-overexpressing cultured human muscle fibers proteasome inhibition enhances phosphorylation of AbetaPP751 and GSK3beta activation: effects mitigated by lithium and apparently relevant to sporadic inclusion-body myositis. J Neurochem 2010; 112: 389-396.

(c) (i) $(-)($ Cell Death and Disease is an open-access journal published by Nature Publishing Group. This work is licensed under a Creative Commons Attribution-NonCommercialNoDerivs 3.0 Unported License. To view a copy of this license, visit http://creativecommons.org/licenses/by-nc-nd/3.0/

Supplementary Information accompanies this paper on Cell Death and Disease website (http://www.nature.com/cddis) 